\title{
Time-Frequency Analysis of Partial Discharge Current Pulses in Different Gas Environment under Lightning Impulse
}

\author{
Kemal Arikan, Emel Önal, Serhat Şeker \\ Department of Electrical Engineering, Faculty of Electrical and Electronics, Istanbul Technical University, 34469, Istanbul, \\ Turkey,kemalarikan.itu@gmail.com
}

\begin{abstract}
This paper deals with a time-frequency analysis of the measured partial discharge (PD) currents in different insulation gases. These gas environments consist of a pure $\mathrm{SF}_{6}$ (sulphur-hexafluoride) and sulphur-hexafluoride and nitrogen $\left(1 \% \mathrm{SF}_{6}+99 \% \mathrm{~N}_{2}\right)$ mixture, under both positive and negative lightning impulse (LI) voltage stresses. In this study, the short time Fourier transform was used to extract the timefrequency information of PDs for different gases at different pressures, and these results were compared to each other. Thus, the relationship between the time, amplitude, and frequency of PD currents was studied. Moreover, some statistical formulas, such as mean, standard deviation, kurtosis, and skewness were applied to the time-dependent PD current data. As a result, a correlation between obtained statistical results and PD frequencies was examined. In most cases, the frequency of partial discharge decreased when the pressure increased. The amplitude of the partial discharges for negative polarity was more than that for positive polarity gas insulations. The partial discharge amplitudes of the pressure of 2 bar were mostly high compared to other pressures. This case demonstrated that $\mathrm{SF}_{6}$ had a maximum minimum character in terms of breakdown. The partial discharge frequency of a $1 \% \mathrm{SF}_{6}$ mixture was higher than that of pure $\mathrm{SF}_{6}$. It is thought that $\mathrm{SF}_{6}$ suppresses the discharge frequency, and statistical evaluations support the experimental results.
\end{abstract}

Keywords: IEC 60270, Partial Discharges, Short Time Fourier Transform, Lightning impulse.

\section{INTRODUCTION}

The IEC 60270 standard states, "Partial discharge (PD) is localized electrical discharge that only partially bridges the insulation between conductors and which can or cannot occur adjacent to a conductor." The standard also explains the occurrence of these discharges as pulses with duration much lower than $1 \mu \mathrm{s}[1]$.

Most of the energy system faults happen due to defects occurring in the insulation of high voltage (HV) equipment; thus very high electric field intensities in insulation cause PDs. Ongoing PDs cause degradation in the insulation of the $\mathrm{HV}$ equipment over time. The condition monitoring of $\mathrm{PD}$ in power systems is required to mitigate the insulation breakdown resulting from PD. Partial discharge analysis in high voltage apparatus is comprised of PD monitoring, estimation, data processing, and evaluating systems. The transition of time-frequency domain and data processing by filtering are essential parts of PD signal analysis [2].

The PD pulses under lightning impulse (LI) voltage are aperiodic and non-stationary signals dissimilar to under AC voltages. So, the classic Fourier transform is not an effective method for analyzing PD pulses because the classical Fourier transform eliminates the time information of pulses. Nevertheless, some researchers have used time-frequency transformation methods to examine the detailed information of PD pulses. For example, Z. Ren [3] used the short-time Fourier transform (STFT), Wigner-Ville distribution, and the Gabor transform to analyze the PD pulses on a defect in the $220 \mathrm{kV}$ GIS bus system, W. Li [4] applied a calibration pulse signal to a $110 \mathrm{kV} \mathrm{HV}$ cable outdoors and then extracted the PD waveform from background noise by using the short-time Fourier transform. S. M. Bhatt [5] created a computer simulator for epoxy resin containing a cylindrical void deformity inside to generate PD activity and then applied STFT to PD currents under different AC voltage levels. J. Dikun et al. [6] analyzed the frequencies between the negative chopped impulse voltage and the negative impulse current sphere-plane electrode system by STFT and found coherence between them. T. Pinpart et al. [7] applied spectrogram analysis to data obtained from ultra-high frequency (UHF) sensors and distinguished different PD sources using these results.

The aim of this paper was to examine PD current pulses under different polarity lightning impulse voltages in different gas insulated mediums such as sulphur-hexafluoride $\left(\mathrm{SF}_{6}\right)$ and nitrogen $\left(\mathrm{N}_{2}\right)$ with different pressures by its timefrequency characteristics, and amplitudes. The intention was to analyze the non-uniform electric field distribution in $\mathrm{HV}$ equipment since it is a commonly used practice, so experiments were conducted with sphere-needle electrode 
configuration. The dielectric environment, gas pressure, and lightning impulse voltage polarity effects on PD current pulse frequencies were examined as variable parameters. Furthermore, the statistics of PD current data were analyzed to demonstrate the effect of these statistic parameters on the PD current pulse frequency.

\section{MATHEMATICAL BACKGROUND}

In this section, the mathematical background of the shorttime Fourier transform and statistical formulas such as mean, standard deviation, skewness, and kurtosis are given.

\section{A. Short time Fourier transform}

Many researchers use the classical Fourier transform in signal processing, but the Fourier transform has some disadvantages. For example, when the signal is nonstationary, it means that it contains transient signals and its characteristics change overtime, and classical Fourier transform cannot explain the frequency information in terms of time because the time information is lost. So, STFT is a specially developed form of the classical Fourier transform introduced by Dennis Gabor in 1946 [8].

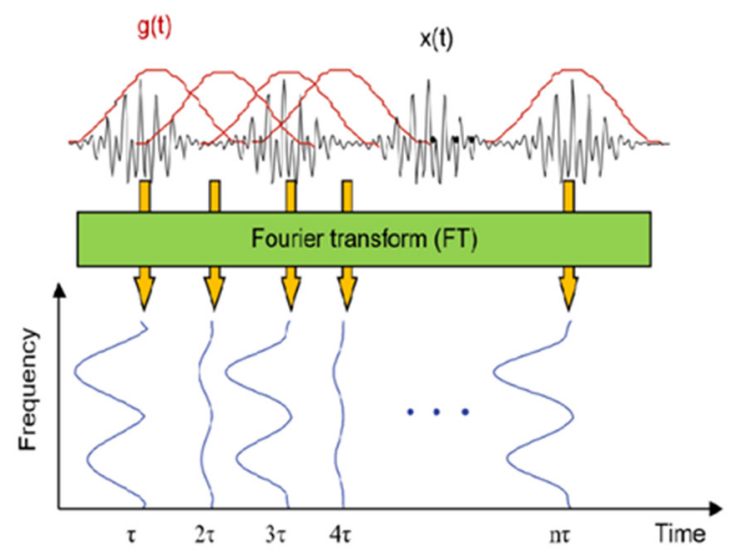

Fig.1. Schematic diagram of STFT on a non-stationary signal $\mathrm{x}(\mathrm{t})$ [9].

In Fig.1., $\mathrm{x}(\mathrm{t})$ is a non-stationary signal to which STFT is applied by a window function $\mathrm{g}(\mathrm{t})$. The window function is centered at time $\tau$. A time localized Fourier transform is implemented on the $\mathrm{x}(\mathrm{t})$ signal inside the window for each particular time. The window is continuously shifted by $\tau$ along the time line, and so a different Fourier transform is executed; thus, by these sequential procedures, a Fourier transform of the whole signal can be done. It is assumed that signal part within the window function is roughly stationary. Finally, the time domain signal is decomposed into a twodimensional time-frequency model.

Hereby, the mathematical equation of STFT of a given signal $\mathrm{x}(\mathrm{t})$ is expressed as below in equation (1).

$$
\operatorname{STFT}(\tau, f)=\int x(t) g(t-\tau) e^{-j 2 \pi f t} d t
$$

There are some different window functions such as Hanning, Hamming, and Gaussian for different applications.
The Gaussian window is used for transient signal analysis. Hanning and Hamming window functions are suitable for narrow band random signals. By the uncertainty principle, time resolution and frequency resolution of a signal cannot both be high at the same time [9].

\section{B. Statistical formulas}

Some researchers use the statistical parameters of PD data to classify the PD sources inside high voltage insulation systems. These statistical parameters are mean, standard deviation, skewness, and kurtosis [10].

In this paper, statistical parameters are used to examine the effect of these parameters on the frequency of PD current peaks.

$$
\text { Mean value }(\mu)=\frac{1}{N} \sum_{i=1}^{N} x_{i}
$$

In equation (2), $\mathrm{x}$ is the random variables of $\mathrm{PD}$ magnitude, and $\mathrm{N}$ is the number of PD data. The mean value $(\mu)$ of PD current data is calculated by equation (2)

$$
\text { Standard deviation }(\sigma)=\sqrt{\frac{\sum_{\mathrm{i}=1}^{\mathrm{N}}\left(\mathrm{x}_{\mathrm{i}}-\mu\right)^{2}}{\mathrm{~N}-1}}
$$

The standard deviation $(\sigma)$ as seen in equation (3) is the amount of distribution or variation of data values in a set. It is the square root of variance.

$$
\text { Skewness }\left(\mathrm{S}_{\mathrm{k}}\right)=\frac{\sum_{\mathrm{i}=1}^{\mathrm{N}}\left(\mathrm{x}_{\mathrm{i}}-\mu\right)^{3}}{\sigma^{3}}
$$

Skewness (equation (4)) is a function of the asymmetry quantity of data according to normal distribution. If skewness is zero $\left(S_{k}=0\right)$, then the distribution is symmetric around the mean value $(\mu)$ of data. If skewness is positive $\left(S_{k}>0\right)$, then the distribution of data expands more to the right of the mean value $(\mu)$. If skewness is negative $\left(S_{k}<0\right)$, then the distribution of data expands more to the left of the mean value $(\mu)$.

$$
\operatorname{Kurtosis}\left(\mathrm{K}_{\mathrm{u}}\right)=\frac{\sum_{\mathrm{i}=1}^{\mathrm{N}}\left(\mathrm{x}_{\mathrm{i}}-\mu\right)^{4}}{\sigma^{4}}
$$

Kurtosis (equation (5)) is a measure of sharpness of distribution. If the distribution is sharper than the normal distribution, then kurtosis gets high values. On the other hand, if the distribution of data is flatter than the normal distribution, then kurtosis gets low values.

\section{SCHEMATIC DIAGRAM OF MEASUREMENT SET UP AND DATA}

In the experimental set up, test electrodes were inside a pressure vessel. The above electrode inside the vessel is spherical; the below electrode was rod shaped in the length of $1 \mathrm{~cm}$ on a plane electrode and the diameter of the rod was $1 \mathrm{~mm}$. The spacing between the two electrodes was $5 \mathrm{~cm}$, and the diameter of the sphere electrode was $5 \mathrm{~cm}$. The insulation in the vessel was changed by two different conditions, pure sulphur-hexafluoride $\left(100 \% \mathrm{SF}_{6}\right)$ and a sulphur-hexafluoride and nitrogen $\left(1 \% \mathrm{SF}_{6}+99 \% \mathrm{~N}_{2}\right)$ mixture. The pressures of both dielectrics inside the pressure vessel were changed as follows: 1 bar, 2 bar, and 3 bar. Lightning impulse voltage 
was applied to the upper electrode. This impulse voltage was generated by $1 \mathrm{MV}, 50 \mathrm{~kJ}$ via a Marx type impulse generator. In the experiment, the polarity of the lightning impulse voltage was changed for each different dielectric and pressure. A capacitive voltage divider, which has a 1:990 nominal ratio, was used for measuring the lightning impulse voltage. For the measuring of impulse currents, a measuring impedance circuit and coaxial cable were used. All data were recorded by a HIAS 743 digital oscilloscope that had a 12-bit vertical resolution at $120 \mathrm{mega}$ sample/sec. The sampling frequency of all digital data was 1 Giga sample/sec. All measurements complied with the requirements given in the IEC standard. A schematic diagram of measurement set up is shown in Fig.2.

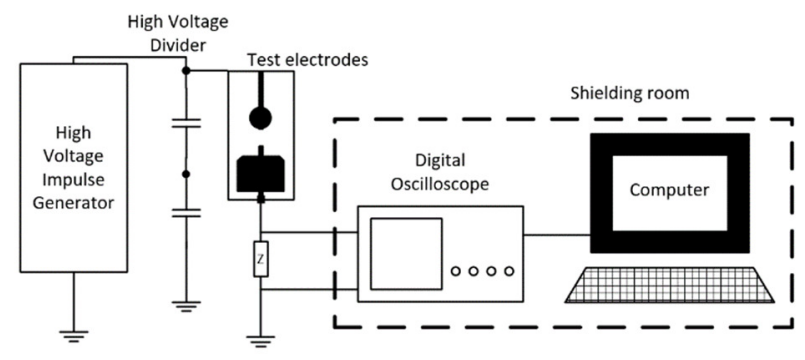

Fig.2. Experimental set up.

In this study, positive polarity and negative polarity lightning impulse voltages were applied to electrodes in pure sulphur-hexafluoride $\left(100 \% \mathrm{SF}_{6}\right)$ and for $1 \% \mathrm{SF}_{6}+99 \% \mathrm{~N}_{2}$. Three experimental data were examined for each pressure under each polarity, and results were obtained from three samples of each condition.

\section{SHORT TIME FOURIER TRANSFORM OF EXPERIMENTAL DATA}

In this section, STFT analysis is applied to the PD currents. As a sample analysis, LI voltage applied to test electrodes for 3 bar pressure and $100 \% \mathrm{SF}_{6}$ media is shown in Fig.3.a).

When LI voltage was applied, the PD current signal was measured by measuring impedance, and its amplitude was recorded by oscilloscope as voltage, and the plotted PD signal is shown in Fig.3.b).

In Fig.3.b), peaks in the red rectangle are partial discharges and easily recognized. These peaks can be more than one, depending on the experiments. When PD current peaks are more than one, the time, frequency, and values of all peaks are examined individually, and then their averaged values are recorded.

Before starting the STFT analysis, the data range of the total PD signal to be analyzed was extracted. This range is demonstrated in Fig.4. in the area covered by the red rectangle. The reason for choosing this area was to eliminate the low amplitude current peaks that occur before the LI voltage starts to rise and the high amplitude current peaks that occur after the breakdown moment of the media. Partial discharges are usually localized between these two conditions. The extracted part was plotted again, and the data number was nearly 1000 and is displayed in Fig.5.

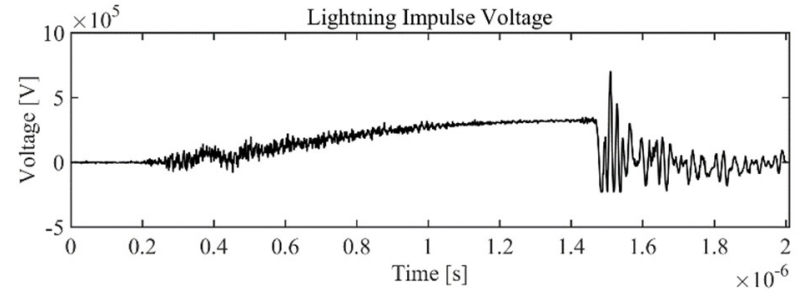

Fig.3.a) Applied lightning impulse voltage waveform for 3 bar pressure and $100 \% \mathrm{SF}_{6}$.

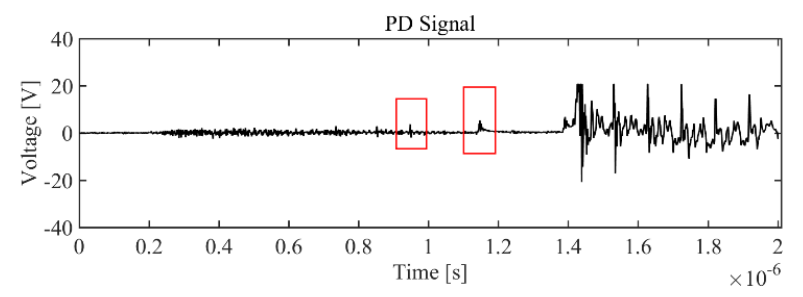

Fig.3.b) Voltage amplitude of PD current on measurement impedance.

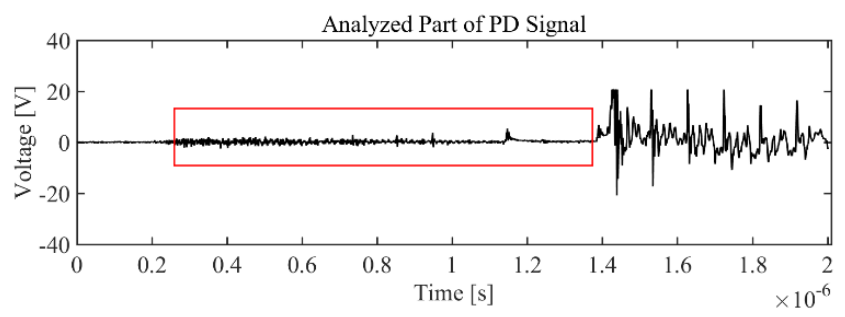

Fig.4. Analyzed part of PD current signal.

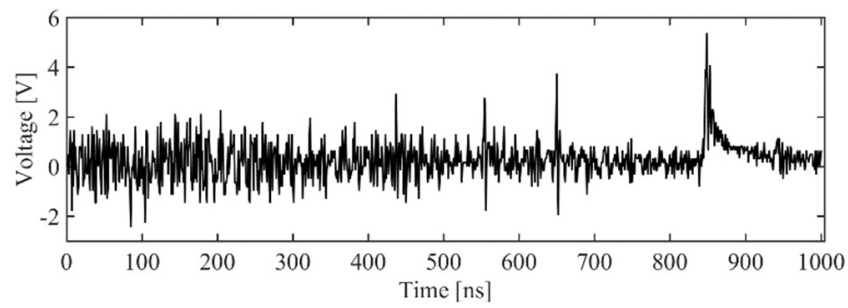

Fig.5. Detailed part of Fig.4.

In this study, the sampling frequency of $1 \mathrm{GHz}$ was chosen. The Hanning type was chosen as the window function for STFT, and window size was 16 . The FFT number was chosen as nearly half of the data number, 512. STFT of Fig.5. is shown in Fig.6.

The spectrogram in Fig.6. is an energy spectrum which is shown by different colors that indicate different intensities of energy. Here, the frequency range at the time of the PD currents is shown as dark red colors. As shown in Fig.6., the area inside the black circle is the highest energy of the whole spectrum. As seen from experimental results, the PD current occurs at $1.14 \mu$ s and its amplitude is $5.37 \mathrm{~V}$.

The frequency spectrum was obtained by enlarging the area inside the black circle in Fig.6., as shown in Fig.7. The frequency boundaries of this highest energy area are between $0.976 \mathrm{MHz}$ and $28.32 \mathrm{MHz}$. As a result, the frequency of the PD current at time $1.14 \mu$ s is $14.648 \mathrm{MHz}$. All PD current frequencies are obtained in chapter 5 . 


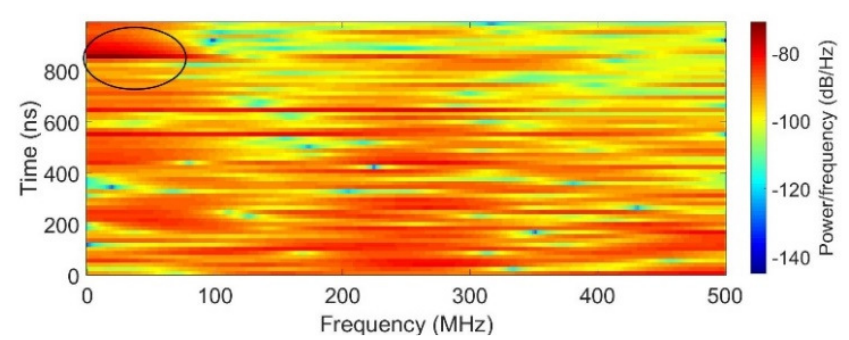

Fig.6. STFT time-frequency spectrum for data in Fig.5.

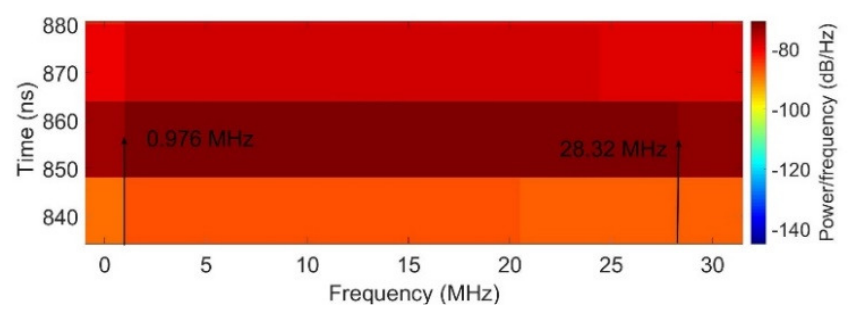

Fig.7. The STFT time-frequency spectrum for data in Fig.6.

\section{RESULTS AND DISCUSSION}

\section{A. Application of stft analysis to experimental signal}

The PD current time, frequency, and amplitude values, which are obtained by using STFT for different ambient, are seen as in Table 1., Table 2., Table 3. and Table 4.

According to the results, under positive and negative polarity LI voltage, as the amplitude values of the PD currents increase, the frequencies show a tendency to decrease. There is also a relationship between the amplitude and the time of the PD currents. The amplitude values of the PDs that appear in the early period before breakdown voltage are low, and the PDs that approach the moment of breakdown in the late period are high.

Table 1. PD values for $100 \% \mathrm{SF}_{6}$ under positive polarity LI voltage.

\begin{tabular}{|c|c|c|c|c|}
\hline $\begin{array}{c}\text { Pressure } \\
\text { (Bar) }\end{array}$ & $\begin{array}{c}\text { Experiment } \\
\text { Number }\end{array}$ & $\begin{array}{c}\text { Frequency } \\
\text { (MHz) }\end{array}$ & $\begin{array}{c}\text { Time } \\
(\mu \mathrm{s})\end{array}$ & $\begin{array}{c}\text { Amplitude } \\
\text { (V) }\end{array}$ \\
\hline \multirow{3}{*}{1} & 1 & 11.718 & 1.22 & 4.072 \\
\hline & 2 & 11.718 & 1.03 & 2.769 \\
\hline & 3 & 10.738 & 1.06 & 3.747 \\
\hline \multicolumn{2}{|c|}{ Average } & 11.391 & 1.10 & 3.529 \\
\hline \multirow{3}{*}{2} & 1 & 10.252 & 1.25 & 4.398 \\
\hline & 2 & 9.763 & 1.22 & 7.44 \\
\hline & 3 & 10.718 & 0.83 & 8.47 \\
\hline \multicolumn{2}{|c|}{ Average } & 10.244 & 1.101 & 6.769 \\
\hline \multirow{3}{*}{3} & 1 & 10.253 & 1.04 & 4.555 \\
\hline & 2 & 14.158 & 1.16 & 6.434 \\
\hline & 3 & 9.112 & 1.017 & 3.584 \\
\hline \multicolumn{2}{|c|}{ Average } & 11.174 & 1.07 & 4.857 \\
\hline
\end{tabular}

According to the results from Table 1., Table 2., Table 3. and Table 4., the PD pulse amplitude variation with respect to the frequency for 1 bar pressure and the different gas medium under positive and negative LI voltages is shown in Fig.8. Moreover, the PD pulse amplitude changes with respect to the time for 2 bar pressure and different gas medium under positive and negative LI voltages is shown in Fig.9.

Table 2. PD values for $100 \%$ SF6, under negative polarity LI voltage.

\begin{tabular}{|c|c|c|c|c|}
\hline $\begin{array}{c}\text { Pressure } \\
\text { (Bar) }\end{array}$ & $\begin{array}{c}\text { Experiment } \\
\text { Number }\end{array}$ & $\begin{array}{c}\text { Frequency } \\
\text { (MHz) }\end{array}$ & $\begin{array}{l}\text { Time } \\
(\mu s)\end{array}$ & $\begin{array}{c}\text { Amplitude } \\
\text { (V) }\end{array}$ \\
\hline \multirow{3}{*}{1} & 1 & 10.742 & 1.16 & -6.62 \\
\hline & 2 & 13.668 & 0.924 & -4.991 \\
\hline & 3 & 19.526 & 1.02 & -4.31 \\
\hline \multicolumn{2}{|c|}{ Average } & 14.645 & 1.03 & -5.307 \\
\hline \multirow{3}{*}{2} & 1 & 12.694 & 1.32 & -9.61 \\
\hline & 2 & 12.691 & 1.19 & -9.367 \\
\hline & 3 & 12.693 & 0.395 & -12.706 \\
\hline \multicolumn{2}{|c|}{ Average } & 12.693 & 0.968 & -10.561 \\
\hline \multirow{3}{*}{3} & 1 & 14.321 & 1.264 & -4.529 \\
\hline & 2 & 13.668 & 1.212 & -10.502 \\
\hline & 3 & 12.715 & 1.46 & -9.525 \\
\hline \multicolumn{2}{|c|}{ Average } & 13.568 & 1.312 & -8.185 \\
\hline
\end{tabular}

Table 3. PD values for $1 \% \mathrm{SF} 6+99 \% \mathrm{~N} 2$ under positive polarity LI voltage.

\begin{tabular}{|c|c|c|c|c|}
\hline $\begin{array}{c}\text { Pressure } \\
\text { (Bar) }\end{array}$ & $\begin{array}{c}\text { Experiment } \\
\text { Number }\end{array}$ & $\begin{array}{c}\text { Frequency } \\
(\mathrm{MHz})\end{array}$ & $\begin{array}{l}\text { Time } \\
(\mu s)\end{array}$ & $\begin{array}{c}\text { Amplitude } \\
\text { (V) }\end{array}$ \\
\hline \multirow{3}{*}{1} & 1 & 19.526 & 0.397 & 4.77 \\
\hline & 2 & 29.29 & 0.429 & 5.747 \\
\hline & 3 & 19.525 & 0.759 & 4.77 \\
\hline \multicolumn{2}{|c|}{ Average } & 22.78 & 0.528 & 5.09 \\
\hline \multirow{3}{*}{2} & 1 & 8.788 & 1.24 & 4.11 \\
\hline & 2 & 18.553 & 1.36 & 12.26 \\
\hline & 3 & 15.623 & 1.55 & 7.702 \\
\hline \multicolumn{2}{|c|}{ Average } & 14.321 & 1.38 & 8.024 \\
\hline \multirow{3}{*}{3} & 1 & 14.645 & 1.27 & 12.591 \\
\hline & 2 & 18.553 & 1.10 & 3.884 \\
\hline & 3 & 16.598 & 1.05 & 4.444 \\
\hline \multicolumn{2}{|c|}{ Average } & 16.598 & 1.13 & 6.973 \\
\hline
\end{tabular}

Table 4. PD values for $1 \% \mathrm{SF}_{6}+99 \% \mathrm{~N}_{2}$ under negative polarity LI voltage.

\begin{tabular}{|c|c|c|c|c|}
\hline $\begin{array}{c}\text { Pressure } \\
\text { (Bar) }\end{array}$ & $\begin{array}{c}\text { Experiment } \\
\text { Number }\end{array}$ & $\begin{array}{c}\text { Frequency } \\
\text { (MHz) }\end{array}$ & $\begin{array}{l}\text { Time } \\
(\mu s)\end{array}$ & $\begin{array}{c}\text { Amplitude } \\
\text { (V) }\end{array}$ \\
\hline \multirow{3}{*}{$(20.0)$} & 1 & 13.67 & 0.687 & -14.78 \\
\hline & 2 & 29.295 & 0.694 & -8.262 \\
\hline & 3 & 19.525 & 0.721 & -24.88 \\
\hline \multicolumn{2}{|c|}{ Average } & 20.83 & 0.7 & -15.974 \\
\hline \multirow{3}{*}{2} & 1 & 13.667 & 1.03 & -4.456 \\
\hline & 2 & 15.622 & 0.818 & -6.086 \\
\hline & 3 & 15.622 & 0.976 & -6.411 \\
\hline \multicolumn{2}{|c|}{ Average } & 14.970 & 0.940 & -5.651 \\
\hline \multirow{3}{*}{3} & 1 & 15.62 & 1.06 & -12.59 \\
\hline & 2 & 11.715 & 1.018 & -5.855 \\
\hline & 3 & 10.737 & 0.903 & -11.776 \\
\hline \multicolumn{2}{|c|}{ Average } & 12.690 & 0.994 & -10.074 \\
\hline
\end{tabular}

While the amplitude of PDs is low, the recurrence of PDs is high; thus, it is thought that frequency shows a rising tendency. On the other hand, when the amplitude of PDs is high, it can be said that the frequency will decrease because 
high amplitudes of PDs rarely occur. However, in some cases, high amplitude PDs can be frequent because of the stochastic nature of PDs. In this case, the frequency may tend to increase.

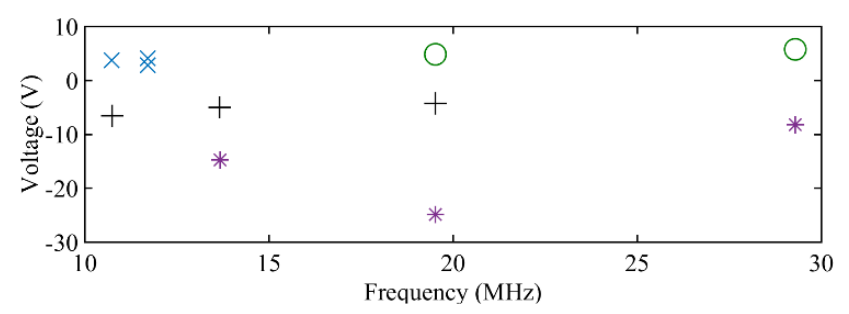

Fig.8. PD amplitude variation with respect to frequency for 1 bar pressure. $x$ : $100 \% \mathrm{SF}_{6}$, Positive LI voltage, $+: 100 \% \mathrm{SF}_{6}$, Negative LI voltage, o: $1 \% \mathrm{SF}_{6}+99 \% \mathrm{~N}_{2}$, Positive LI voltage, * $1 \% \mathrm{SF}_{6}$ $+99 \% \mathrm{~N}_{2}$, Negative LI voltage.

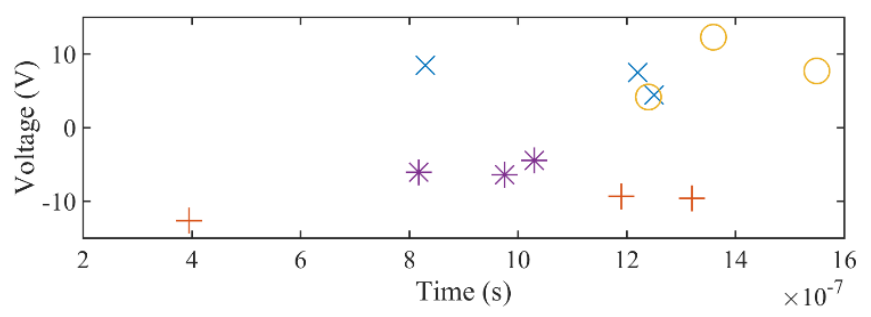

Fig.9. PD amplitude variation with respect to time for 2 bar pressure. $\mathrm{x}$ : $100 \% \mathrm{SF}_{6}$, Positive LI voltage, $+: 100 \% \mathrm{SF}_{6}$, Negative LI voltage, $\circ: 1 \% \mathrm{SF}_{6}+99 \% \mathrm{~N}_{2}$, Positive LI voltage, $*: 1 \% \mathrm{SF}_{6}+$ $99 \% \mathrm{~N}_{2}$, Negative LI voltage.

In general, $\mathrm{PD}$ frequencies of $100 \% \mathrm{SF}_{6}$ negative polarity LI voltage are higher than those of $100 \% \mathrm{SF}_{6}$ positive polarity LI voltage. This case confirmed the polarity effect of partial discharge.

On the other hand, PD frequencies of positive LI for $1 \% \mathrm{SF}_{6}+99 \%$ are higher than PD frequencies of negative LI for $1 \% \mathrm{SF}_{6}+99 \% \mathrm{~N}_{2}$. These results require a stochastic examination for more precise results. For this reason, the statistical research may be seen below.

The PD current frequencies under $1 \% \mathrm{SF}_{6}+99 \% \mathrm{~N}_{2}$ gas mixture are generally higher than the $\mathrm{PD}$ frequencies of $100 \% \mathrm{SF}_{6}$ gas media. This indicates that $\mathrm{SF}_{6}$ is more sensitive to non-uniform fields. It can be said that $\mathrm{SF}_{6}$ suppresses the amplitude and frequency of partial discharge. In addition, the amplitude of partial discharges for the pressure of 2 bar is higher than that of partial discharges for the pressure of 1 and 3 bar. This case indicated that $\mathrm{SF}_{6}$ has abnormal breakdown phenomena at these pressure ranges. As the pressure increased, discharge time increased very little.

\section{B. Statistical analysis}

In this section, statistical values - mean value, standard deviation, skewness, kurtosis of the data range which is voltage amplitudes of PD currents on measurement impedance for $100 \% \mathrm{SF}_{6}$ under positive polarity LI voltage - are calculated as shown in Table 5.,Table 6. and Table 7. The data range to be statistically analyzed was selected in a similar way in the Short-term Fourier Transform section. The data range was chosen between the very low amplitude voltage values which occur on the measurement impedance before LI voltage starts to rise and the high amplitude voltage values which occur on the measurement impedance after the breakdown of dielectric media. Actually, the data range used for STFT analysis is the same as the data range which is used to calculate the statistical values for $100 \% \mathrm{SF}_{6}$ under positive polarity LI voltage.

Table 5. Statistical values of data range which is voltage amplitudes of PD currents on measurement impedance of $100 \% \mathrm{SF}_{6}$ under 1 bar pressure with positive LI voltage.

\begin{tabular}{|c|c|c|c|c|}
\hline $\begin{array}{c}\text { Statistical } \\
\text { Value }\end{array}$ & Exp. 1 & Exp. 2 & Exp. 3 & Average \\
\hline Mean $(\mu)$ & 0.302 & 0.201 & 0.371 & 0.291 \\
\hline $\begin{array}{c}\text { Standard } \\
\text { Deviation }(\sigma)\end{array}$ & 0.649 & 0.572 & 0.693 & 0.638 \\
\hline $\begin{array}{c}\text { Skewness } \\
\left(\mathrm{S}_{\mathrm{k}}\right)\end{array}$ & -0.093 & -0.019 & 0.472 & 0.12 \\
\hline $\begin{array}{c}\text { Kurtosis } \\
\left(\mathrm{K}_{\mathrm{u}}\right)\end{array}$ & 4.882 & 3.941 & 4.508 & 4.444 \\
\hline
\end{tabular}

Table 6. Statistical values of data range which is voltage amplitudes of PD currents on measurement impedance of $100 \% \mathrm{SF}_{6}$ under 2 bar pressure with positive LI voltage.

\begin{tabular}{|c|c|c|c|c|}
\hline $\begin{array}{c}\text { Statistical } \\
\text { Formula }\end{array}$ & Exp.1 & Exp.2 & Exp.3 & Averages \\
\hline Mean $(\mu)$ & 0.350 & 0.536 & 0.328 & 0.405 \\
\hline $\begin{array}{c}\text { Standard } \\
\text { Deviation } \\
(\sigma)\end{array}$ & 0.718 & 1.298 & 0.874 & 0.963 \\
\hline $\begin{array}{c}\text { Skewness } \\
\left(\mathrm{S}_{\mathrm{k}}\right)\end{array}$ & 1.083 & 2.838 & 2.176 & 2.032 \\
\hline $\begin{array}{c}\text { Kurtosis } \\
\left(\mathrm{K}_{\mathrm{u}}\right)\end{array}$ & 7.623 & 17.171 & 23.952 & 16.249 \\
\hline
\end{tabular}

Table 7. Statistical values of data range which is voltage amplitudes of PD currents on measurement impedance of $100 \% \mathrm{SF}_{6}$ under 3 bar pressure with positive LI voltage.

\begin{tabular}{|c|c|c|c|c|}
\hline $\begin{array}{c}\text { Statistical } \\
\text { Formula }\end{array}$ & Exp.1 & Exp.2 & Exp.3 & Averages \\
\hline Mean $(\mu)$ & 0.274 & 0.312 & 0.284 & 0.290 \\
\hline $\begin{array}{c}\text { Standard } \\
\text { Deviation } \\
(\sigma)\end{array}$ & 0.759 & 0.888 & 0.847 & 0.831 \\
\hline $\begin{array}{c}\text { Skewness } \\
\left(\mathrm{S}_{\mathrm{k}}\right)\end{array}$ & 0.669 & 1.633 & 0.376 & 0.893 \\
\hline $\begin{array}{c}\text { Kurtosis } \\
\left(\mathrm{K}_{\mathrm{u}}\right)\end{array}$ & 6.905 & 13.817 & 4.397 & 8.373 \\
\hline
\end{tabular}

The mean value, standard deviation, skewness, and kurtosis are calculated for each experiment in 1 bar, 2 bar, and 3 bar for $100 \% \mathrm{SF}_{6}$, and then their averages are calculated. According to the results, the frequency decreased with the increase in the mean value, standard deviation, skewness, and kurtosis of the data range. This effect can be seen in Fig.10. and Fig. 11. 


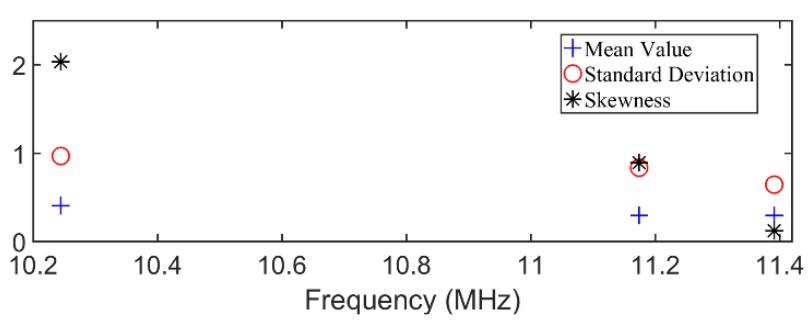

Fig.10. Mean value, standard deviation, and skewness change with respect to frequency.

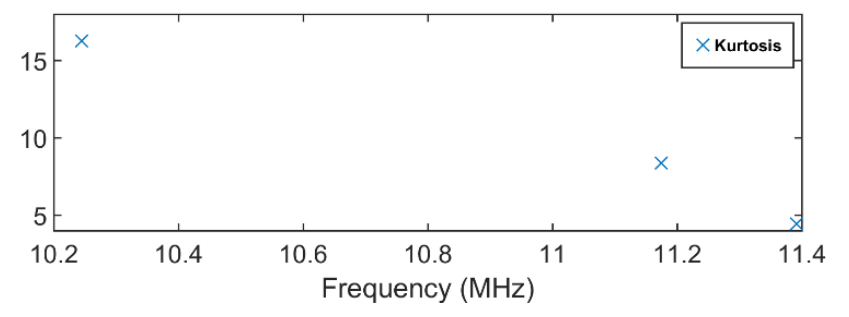

Fig.11. Kurtosis change with respect to frequency.

Since the voltage amplitude of the PD current on measurement impedance at 2 bar is bigger than that of the PD at 1 and 3 bar, the statistical values related to PD at 2 bar are high. Skewness is positive in all cases. That is, it has a large number of PD voltage amplitudes smaller than the average value. Likewise, kurtosis is also positive. These statistical values are normal in the case of electrical breakdown. Kurtosis is also the largest in the pressure of 2 bar.

\section{CONCLUSIONS}

This paper presented a time-frequency analysis of PD currents in different gas environments with different pressure values under different polarities LI voltages. Moreover, the relationship between the statistical parameters of PD current data and frequencies was examined in detail.

According to the experimental results, PD amplitudes for $1 \% \mathrm{SF}_{6}+99 \% \mathrm{~N}_{2}$ were higher than those for $100 \% \mathrm{SF}_{6}$. This case explained that pure $\mathrm{SF}_{6}$ has a more insulating character. No correlation of time between frequencies was observed. Generally, negative PD amplitudes were higher than positive PD amplitudes. Additionally, PD values under 2 bar pressure were higher than PD values of the pressure of 1 and 3 bar; this situation can be interpreted as a characteristic breakdown feature of $\mathrm{SF}_{6}$ gas in non-uniform areas which may be due to the opposite effect of thermal and ionization effects.

According to the STFTs of experimental data, the frequencies of PDs under negative polarity LI voltages were higher than the frequencies of positive polarity LI voltages for pure $\mathrm{SF}_{6}$.

On the other hand, for a $1 \% \mathrm{SF}_{6}+99 \% \mathrm{~N}_{2}$ mixture, the frequencies of PD were higher under positive polarity LI voltages than negative polarity LI voltages.

Moreover, the PD frequencies of $1 \% \mathrm{SF}_{6}+99 \% \mathrm{~N}_{2}$ mixture were higher than $100 \% \mathrm{SF}_{6}$ gas. As a result, the properties of the gases directly affected the frequency of PDs. Adding a certain amount of nitrogen to the sulphur hexafluoride increased the frequencies of PD currents.
Additionally, there was a correlation between the statistical properties of PD current data and frequency of PD currents. According to the results, when mean value, standard deviation, skewness, and kurtosis of time dependent PD current data increased, the average frequencies of PDs in time-dependent $\mathrm{PD}$ data decreased for $100 \% \mathrm{SF}_{6}$. All statistical values were high in the pressure of 2 bar. This case confirmed that $\mathrm{SF}_{6}$ has an abnormal breakdown character in the non-uniform fields.

The method can be further applied for different gas mixtures with different pressures and different electrode systems to analyze certain values such as frequency and statistical values of partial discharge currents in more detail.

\section{REFERENCES}

[1] International Electrotechnical Commission (IEC). (2002). High voltage test techniques - Partial discharge measurements. IEC 60270.

[2] Khayam, U., Surandaka, Y.A. (2016). Design, implementation, and testing of partial discharge signal processing system. In 2016 2nd International Conference of Industrial, Mechanical, Electrical, and Chemical Engineering (ICIMECE). IEEE, 175-179.

[3] Ren, Z., Dong, M., Ren, M., Zhou, H., Miao, J. (2012). The study of partial discharge in GIS under impulse voltage based on time-frequency analysis. In 2012 IEEE International Conference on Condition Monitoring and Diagnosis. IEEE, 694-697.

[4] Li, W., Zhao, J., Meng, S. (2012). Partial discharge time-frequency spectrum analysis and extraction for power cable. In 2012 Asia-Pacific Power and Energy Engineering Conference. IEEE, 1-3.

[5] Bhatt, S.M., Kumar, D., Patel, K. (2018). Partial discharge analysis in time and time-frequency domain of solid dielectric in power transformer. In $20185 \mathrm{th}$ IEEE Uttar Pradesh Section International Conference on Electrical, Electronics and Computer Engineering (UPCON). IEEE, 1-5.

[6] Dikun, J., Onal, E. (2015). Coherence and timefrequency analysis of impulse voltage and current measurements. Journal of Energy in Southern Africa, 26 (2), 118-122.

[7] Pinpart, T., Fletcher, J.E., Judd, M.D. (2008). Methods for distinguishing between partial discharges based on the UHF detection technique. In 2008 International Conference on Condition Monitoring and Diagnosis. IEEE, 1060-1064.

[8] Jaber, A.A., Bicker, R. (2015). A simulation of nonstationary signal analysis using wavelet transform based on LabVIEW and Matlab. In 2014 European Modelling Symposium. IEEE, 138-144.

[9] Gao, R., Yan, R. (2011). Wavelets. Springer.

[10] Ren, L.W., Abd Rahman, M.S., Mohd Ariffin, A. (2017). Classification of partial discharge sources using statistical approach. Indonesian Journal of Electrical Engineering and Computer Science, 6 (3), 537.

Received March 23, 2020 Accepted August 17, 2020 